\title{
The Impact of Endonasal Endoscopic Sinus Surgery on Patients with Chronic Pulmonary Diseases
}

\author{
Basel Al Kadah ${ }^{1, *}$, Gudrun Helmus ${ }^{1}$, Quoc Thai Dinh ${ }^{2}$ and Bernhard Schick ${ }^{1}$ \\ 1 Department of Otorhinolaryngology, University Medical Center Homburg/Saar, D-66424 Homburg, \\ Germany; gudrunhelmus@gmx.de (G.H.); bernhard.schick@uks.eu (B.S.) \\ 2 Department of Pneumology and Experimental Pneumology, University Medical Center Homburg/Saar, \\ D-66424 Homburg, Germany; thai.dinh@uks.eu \\ * Correspondence: basel.al-kadah@uks.eu; Tel.: +49-6841-162-2942; Fax: +49-6841-162-2997
}

Academic Editor: César Picado

Received: 30 March 2017; Accepted: 18 April 2017; Published: 25 April 2017

\begin{abstract}
Introduction: The impact of endoscopic sinus surgery on bronchial asthma has been studied by several groups. According to the latest studies, patients with chronic obstructive pulmonary disease (COPD) seem to have frequent symptoms of chronic rhinosinusitis. Our study compares the impact of endoscopic sinus surgery on both the upper and lower airways of patients with bronchial asthma as well as those with COPD. Methods: This study includes 43 patients (bronchial asthma, $n=32$, COPD, $n=11$ ) undergoing surgical treatment for chronic rhinosinusitis at the ENT-Department, University of Homburg (Homburg, Germany). To assess the effect of sinus surgery, the Sino-Nasal Outcome Test 20 German Adapted Version (SNOT-20 GAV) and St. George's Respiratory Questionnaire (SGRQ) were used both pre- and postoperatively. Results: Both SNOT-20 $(p<0.001)$ and SGRQ $(p=0.021)$ scores improved significantly after sinus surgery. The postoperative improvement in bronchial asthma and COPD was similar in both groups, indicating no difference of the diseases in regards to postoperative symptom improvement. There was no difference indicated in SNOT-20 GAV or SGRQ when grouping patients by polyps, aspirin (ASS) intolerance, allergies, eosinophilia or previous surgery. Conclusions: The treatment of chronic rhinosinusitis by sinus surgery may help to improve the therapy outcome of patients with bronchial asthma as well as patients with COPD.
\end{abstract}

Keywords: endoscopic sinus surgery; COPD; asthma; SGRQ; SNOT-20 GAV

\section{Introduction}

Several research groups have studied the impact of sinus surgery on bronchial asthma and have often noticed the term sinubronchial syndrome [1,2]. However, there is no exact definition for this term. A current chronic rhinosinusitis guideline prefers collaboration with pneumologists [3], and a current study by Ehnhage et al. shows the impact of sinus surgery on the symptoms and lung function parameters in patients with bronchial asthma [4].

Hurst et al. (2006) reported investigations of chronic obstructive pulmonary diseases (COPD) patients showing an inflammatory marker in the sputum and nasal lavage with the finding that the entire respiratory system was affected by the inflammatory reaction [5]. Considering the aspect of inflammatory reactions along the entire respiratory system, recent studies focused on the incidence of rhinosinusitis in patients with chronic bronchitis and COPD. Hens et al. (2008) and Piotrowska et al. (2010) found higher endoscopic rhinosinusitis symptom scores in patients with COPD than in the healthy population [6,7]. In 90 patients with COPD in different disease stages, Kelemence et al. detected clinical criteria for rhinosinusitis in $53 \%$ of the patients [8]. In a review, 
Kim and Rubin (2007) reported that $75 \%$ of all patients with COPD collectively complained of nasal symptoms [9].

There have been multiple studies of bronchial asthma which have examined the influence and impact of sinus surgery on pulmonary disease, however, the influence of sinus surgery on chronic bronchitis has yet to be investigated. The aim of this study is to investigate any changes after performing sinus surgery, in the patients' quality of life and any symptom changes in patients with chronic sinusitis in combination with COPD or with bronchial asthma.

\section{Materials and Methods}

This study includes 43 patients ( 22 male, 21 female) within a period ranging from January 2010 until April 2011. The median age was 50.8 years with a standard deviation of 16 years. The 43 patients (bronchial asthma: $n=32$, COPD: $n=11$ ) underwent surgical treatment for chronic rhinosinusitis in the ENT-Department at Saarland University Medical Center Homburg (Homburg Germany). The patients were examined by pneumologists before being included in the study, and the pneumologists had outlined the definition of a diagnosis of asthma or COPD. All patients gave their informed consent. All procedures performed in studies involving human participants were in accordance with the ethical standards of the institutional research committee and with the 1964 Helsinki declaration and its later amendments or comparable ethical standards.

Of a possible 57 patients, 43 patients were included in the study, which resulted in a $75 \%$ recirculation rate. There were 14 patients who were excluded due to an incomplete data source. Patient data was anonymized. An endonasal endoscopic sinus surgery according to the concepts of functional endoscopic sinus surgery developed by Heerman, Messerklinger, Draf, Wigand and Stammberger [10] was performed in intubation anesthesia after informed consent. Patient file evaluations were retrospective. A medical history and CT-Score according to Lund-Mackay was available for every patient. To assess the effect of functional endoscopic surgery, the Sino-Nasal Outcome Test 20 German Adapted Version (SNOT-20 GAV) and St. George's Respiratory Questionnaire (SGRQ) were used one week preoperatively and for a minimum of three months postoperatively. In addition, the patients' medical treatment for bronchial asthma and COPD was evaluated.

The SGRQ has been developed by Jones et al. [11]. The SGRQ covers the quality of life of patients with COPD, bronchial asthma and bronchiectasis in three sub-scales (symptom, activity and strain) and has been validated for a three month time frame [11]. The SNOT-20 is a validated questionnaire reported by Piccirillo et al. [12], and the SNOT-20 GAV is validated by Baumann et al. [13].

Statistical analysis was tested by using a cross table and Chi-Square-Test. When the requirements for Chi-Square-Test had not been reached, we used the Fisher-Exact-Test. The postoperative run was tested with the Wilcoxon-Test. The Kruskal-Wallis-Test was used to compare more than two groups. We calculated the grade of correlation coefficient according to Spearman. Level $\alpha=0.05$ was defined as a significant level. The statistical data base was analyzed and processed under the application SPSS "Statistical Package for the Social Sciences" (SPSS ${ }^{\circledR}$, IBM Corporation, New York, NY, USA), Version 19 for Windows, as well as Microsoft Office Excel 2007 for Windows (Microsoft Corporation, Redmond, WA, USA).

\section{Results}

There were 43 cases with at least a one-year follow-up that were analyzed after functional endoscopic sinus surgery: There were 32 patients $(74.4 \%)$ with bronchial asthma and 11 patients $(25.6 \%)$ with COPD. There were 29 patients $(67.4 \%)$ who had nasal polyps, 12 patients $(27.9 \%)$ who had aspirin intolerance, and 11 patients $(25.6 \%)$ who had Samter-syndrome. (Figure 1). 


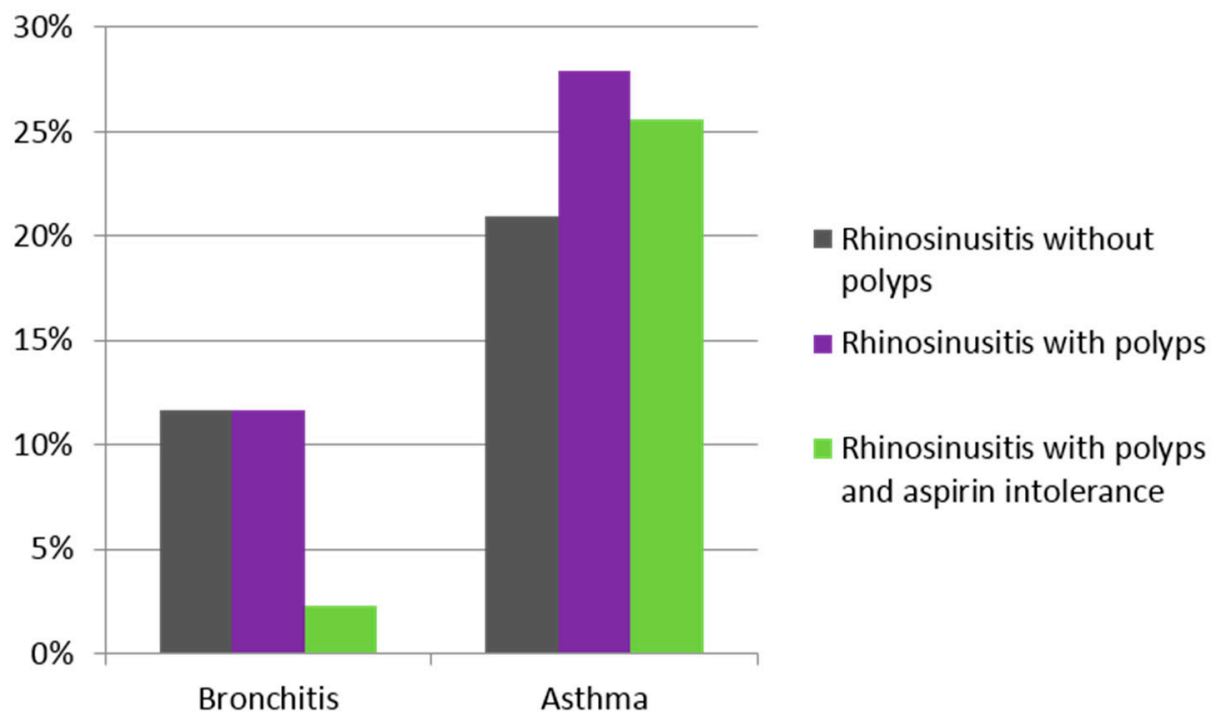

Figure 1. Incidence of Aspirin-Intolerance and nasal polyp.

Eosinophily was found in the histopathological nasal mucosa analysis of 30 patients (73.2\%). Seasonal allergies were reported in 11 patients $(25.6 \%)$, and 22 patients (51.2\%) reported perennial allergies.

The median CT-score according to Lund-Mackay resulted in a preoperative CT-score of 13.5 with no difference between asthma patients and COPD patients $(p=0.277)$. Most patients were on their first or second sinus operation. A third operation was performed in six patients, a fourth operation was performed in two patients and a seventh operation was performed in one patient. The questionnaires were completed in an average postoperative rate of $4.3 \pm 2.2$ month. Figure 2 shows the medication level pre- and post- operative. The medication intake, before and after the sinus surgery, was insignificantly different in both groups according to the result of the Wilcoxon-Test $(p=0.429)$.

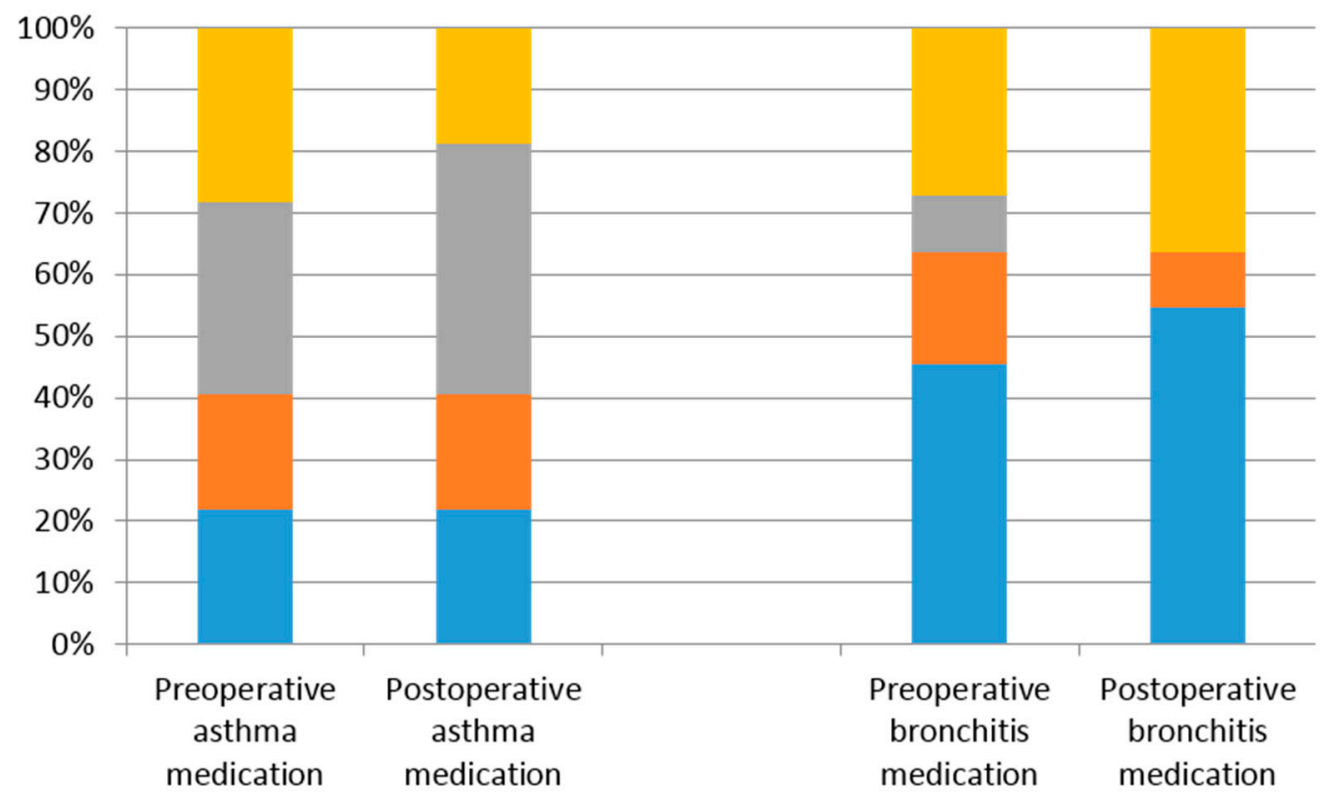

- No medication $=$ Medication level I $\mid$ Medication level II $\mid$ Medication level III

Figure 2. Medication level pre- and postoperative. 
The total score of the SGRQ in all patients shows a preoperative median value of $36.3 \%$ and a postoperative median value of $24.8 \%$ (Figure $3 a$ ). Additionally, the average improvement of the SGRQ score, 8.3 points in asthma patients and 7.9 points in COPD patients, was statistically significant after sinus surgery compared to the preoperative value (Figure 3b, Wilcoxon-Test: $p=0.021$ ). The preoperative median symptom score was $50.2 \%$ and the postoperative score was $44.6 \%$ (Figures 4 and 5). The preoperative median activity score was $42.7 \%$ and the postoperative score was $36.5 \%$. The preoperative median impact score was $26.9 \%$ and the postoperative score was $14.4 \%$. The activity score $(p=0.001)$ and the impact score $(p=0.003)$ were statistically significant, while the symptom score was insignificant with $p=0.132$ (Figure 6).

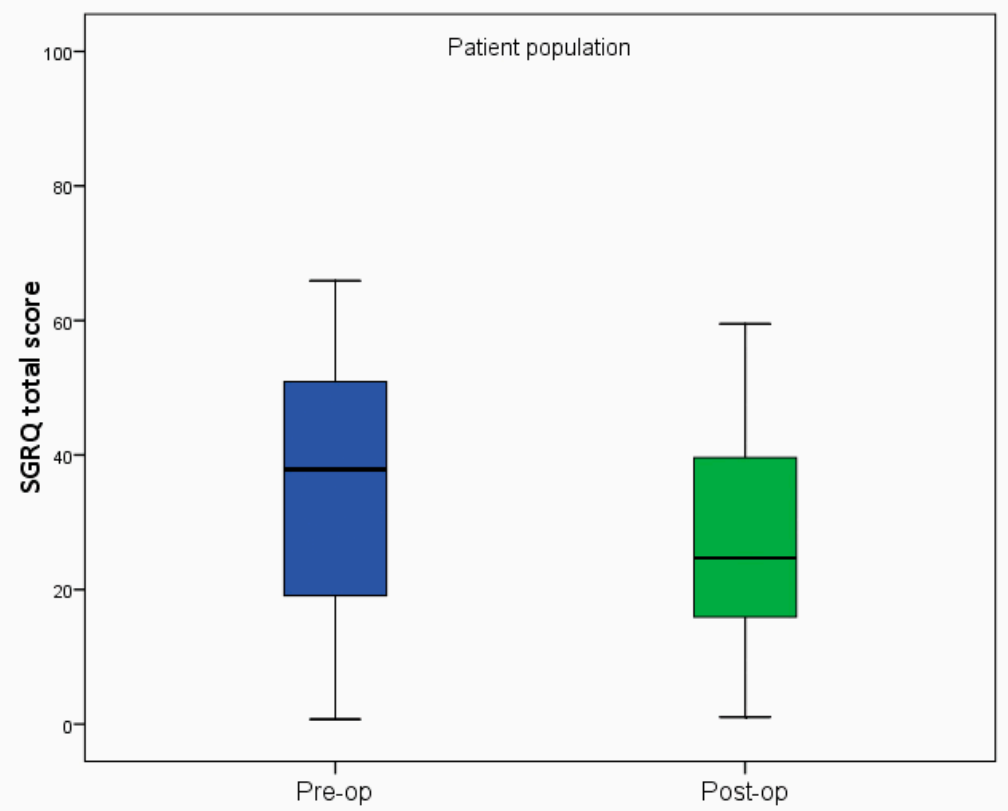

(a)

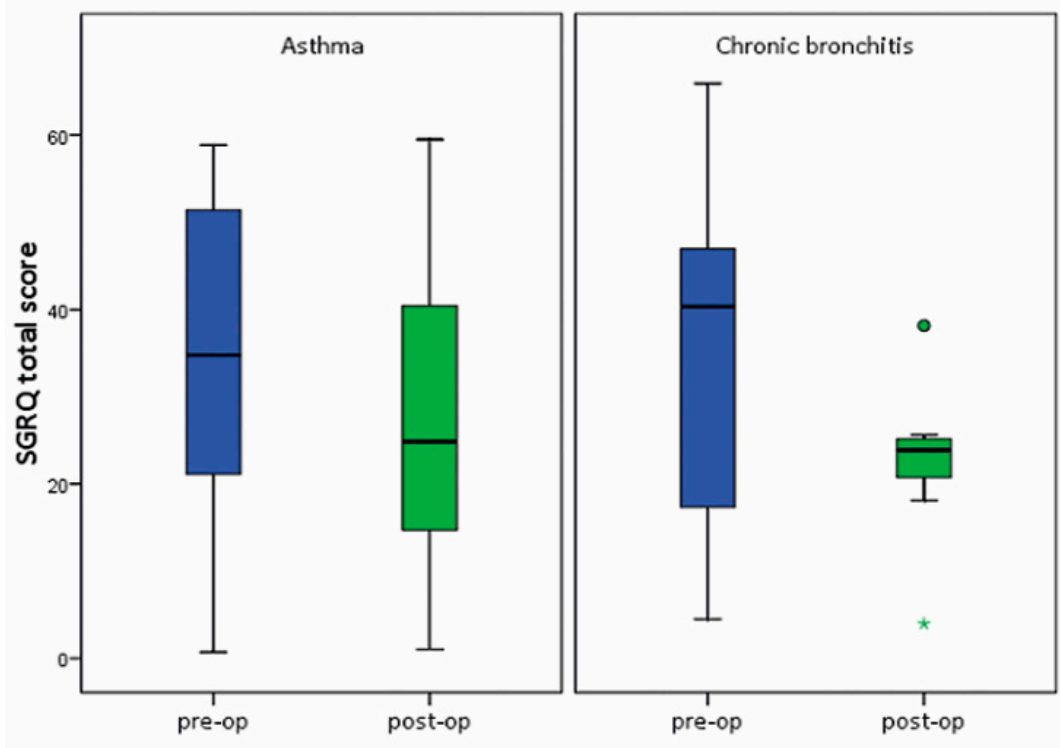

(b)

Figure 3. (a) St. George's Respiratory Questionnaire (SGRQ) total score; (b) SGRQ total score pre-op and post-op in asthma and chronic bronchitis group. pre-op: preoperative; post-op: postoperative. Green asterisk and circle are outliers. 


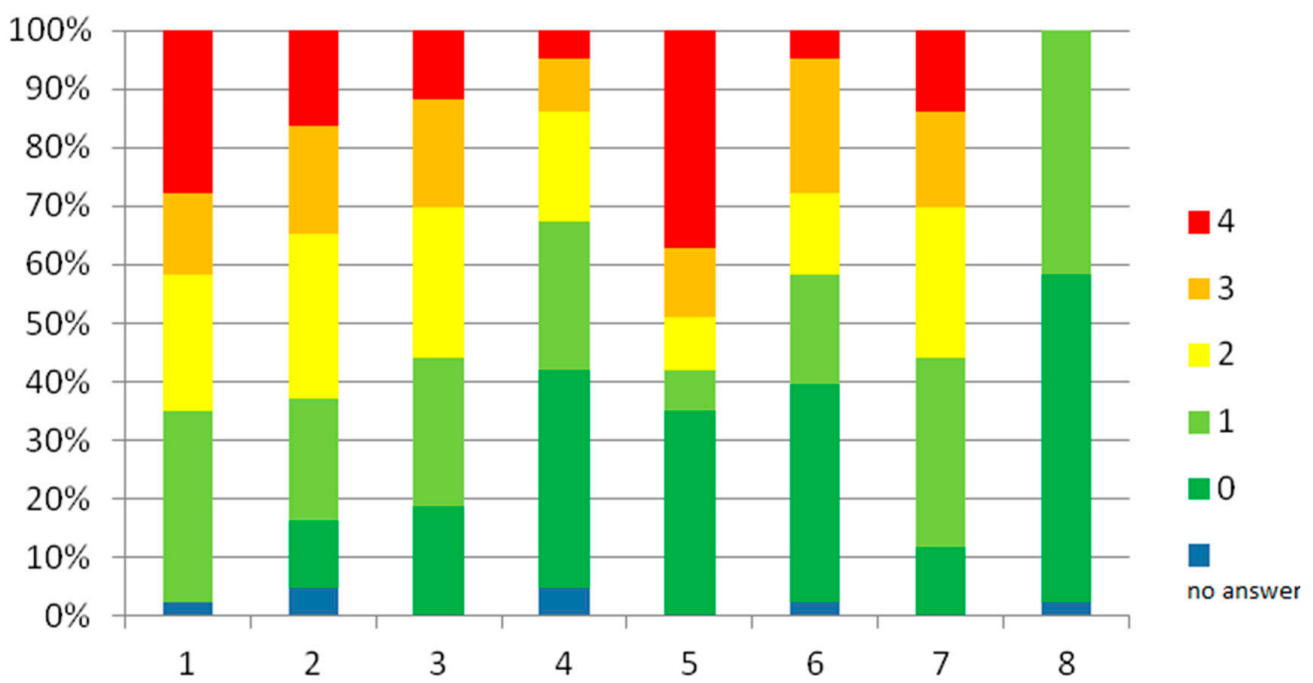

Figure 4. SGRQ subscale symptoms pre-op ( 0 = no symptom, $1=$ light symptom, $2=$ mild symptom, 3 = intense symptom, 4 = heavy symptom, $0 \%$ no impairment to $100 \%$ heavy impairment).

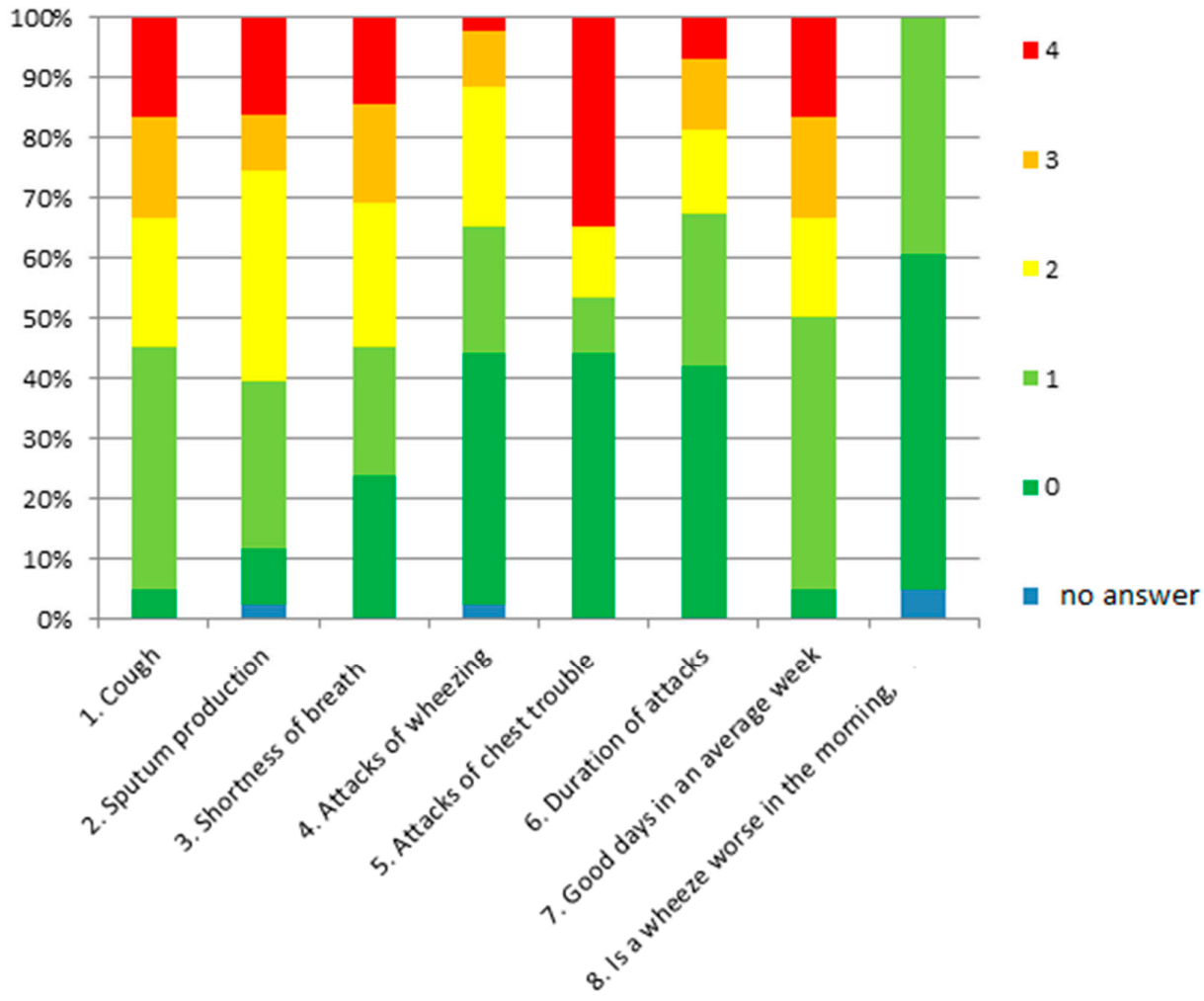

Figure 5. SGRQ subscale symptoms post-op ( 0 = no symptom, $1=$ light symptom, $2=$ mild symptom, $3=$ intense symptom, 4 = heavy symptom, $0 \%$ no impairment to $100 \%$ heavy impairment).

No statistically significant difference was found when comparing the average improvement of the SGRQ in asthma patients and in COPD patient groups both preoperatively and postoperatively, using the Fisher-Exact-Test $(p=0.695)$, (Figure 4). Dividing the groups into patients with polyps, patients without polyps, patients with allergies, patients without allergies, patients with ASS-intolerance, and patients without ASS-intolerance, the Fisher-Exact-Test showed no statistical significance between the different sub-groups preoperatively nor postoperatively. All sub-groups had better results after having sinus surgery. 


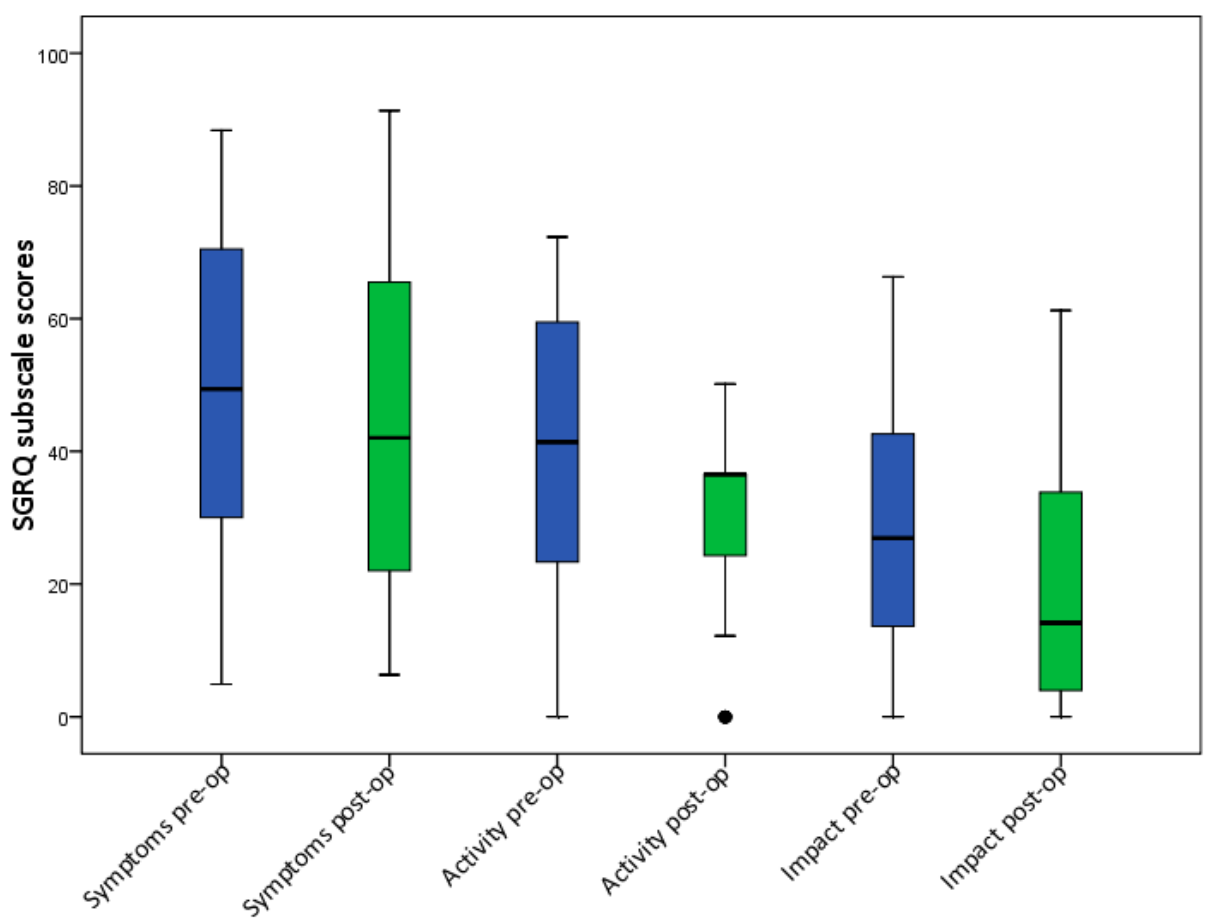

Figure 6. Box plots SGRQ subscale scores pre-op and post-op (black circle is outlier).

(Figures 7-10). The total score of the SNOT-20 GAV in all patients showed a preoperative median value of $44 \%$ and a postoperative median value of $22 \%$ and the change was significant before and after sinus surgery (Wilcoxon-Test: $p<0.001$, Figure 11). Almost all symptoms in SNOT-20 GAV questionnaires were significantly better postoperatively in both groups (Table 1). Dividing the patients into an asthma group and a COPD group did not result in a significant difference between groups, $(p=0.089)$ both groups saw significant changes after sinus surgery.
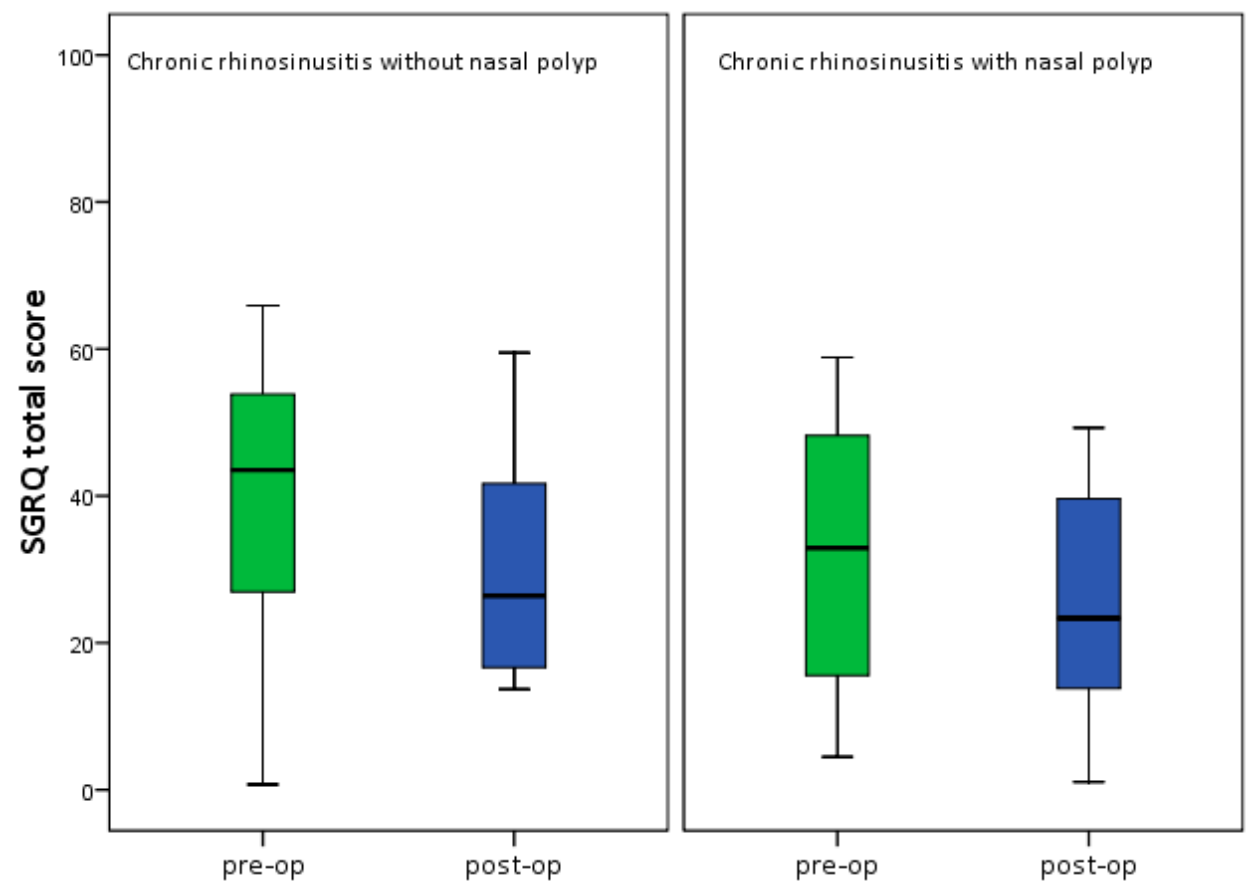

Figure 7. SGRQ total score with or without nasal polyp. 


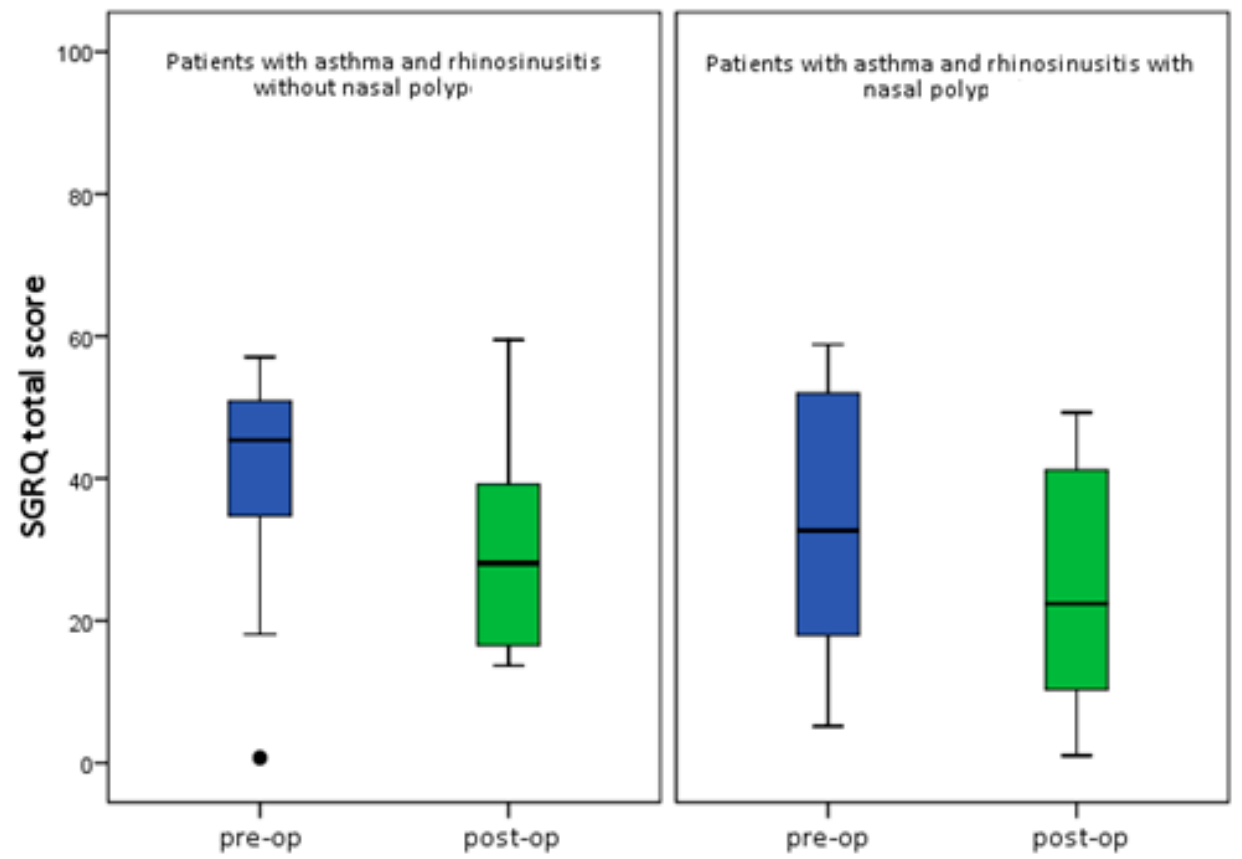

Figure 8. SGRQ total score in asthma patient with or without nasal polyp (black circle is outlier).
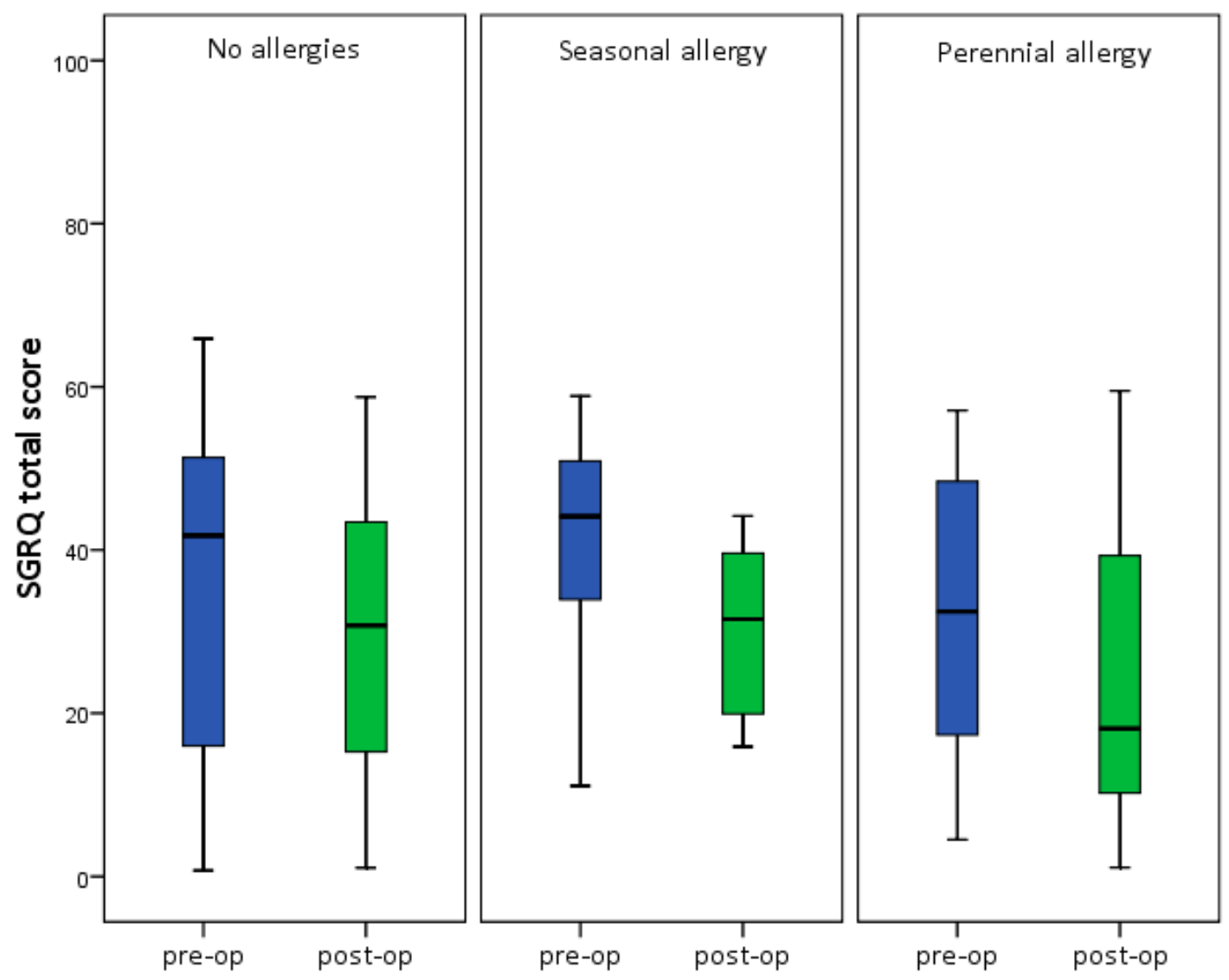

Figure 9. SGRQ total score in patient with or without allergy. 

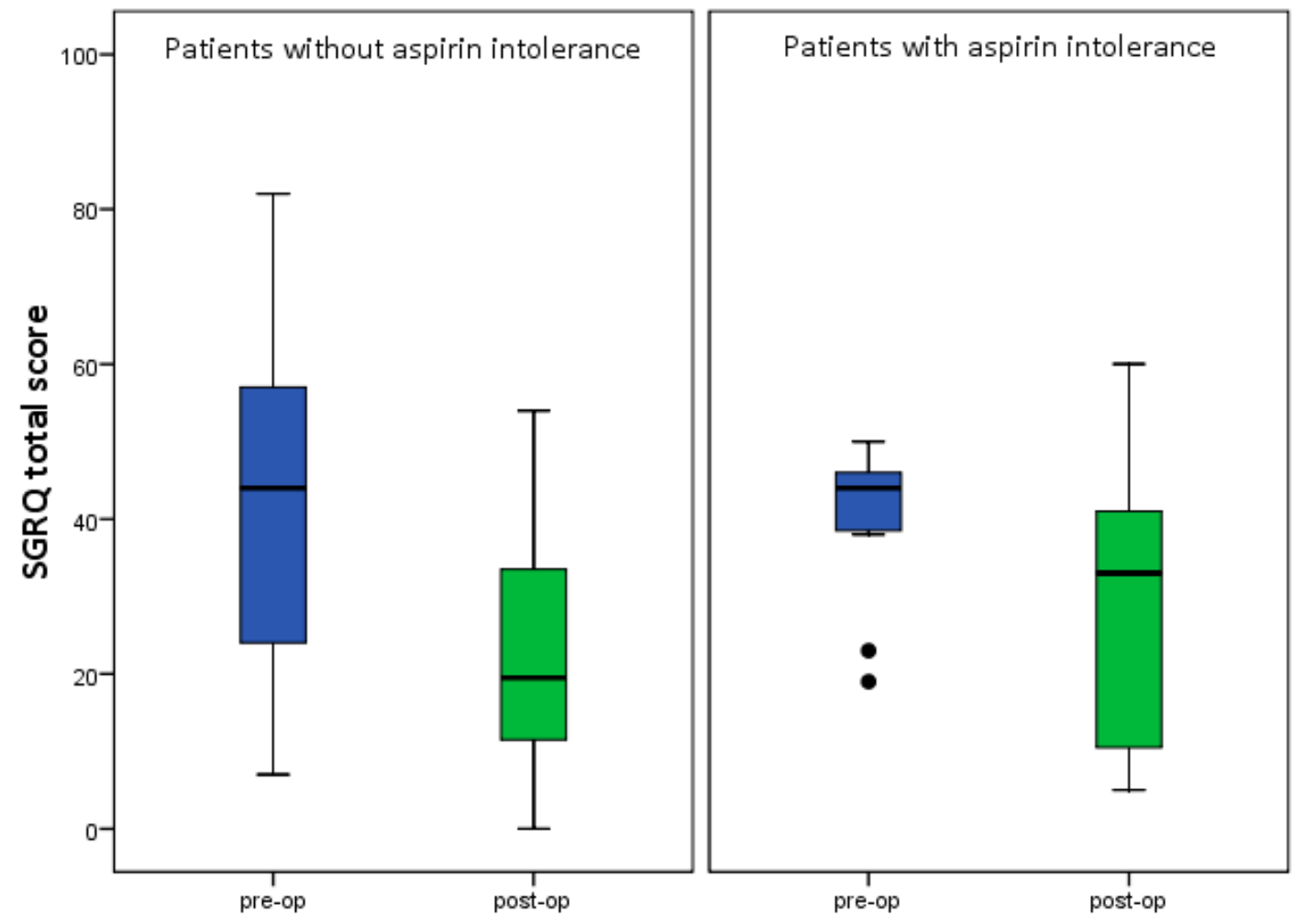

Figure 10. SGRQ total score with or without aspirin intolerance (black circles are outliers).
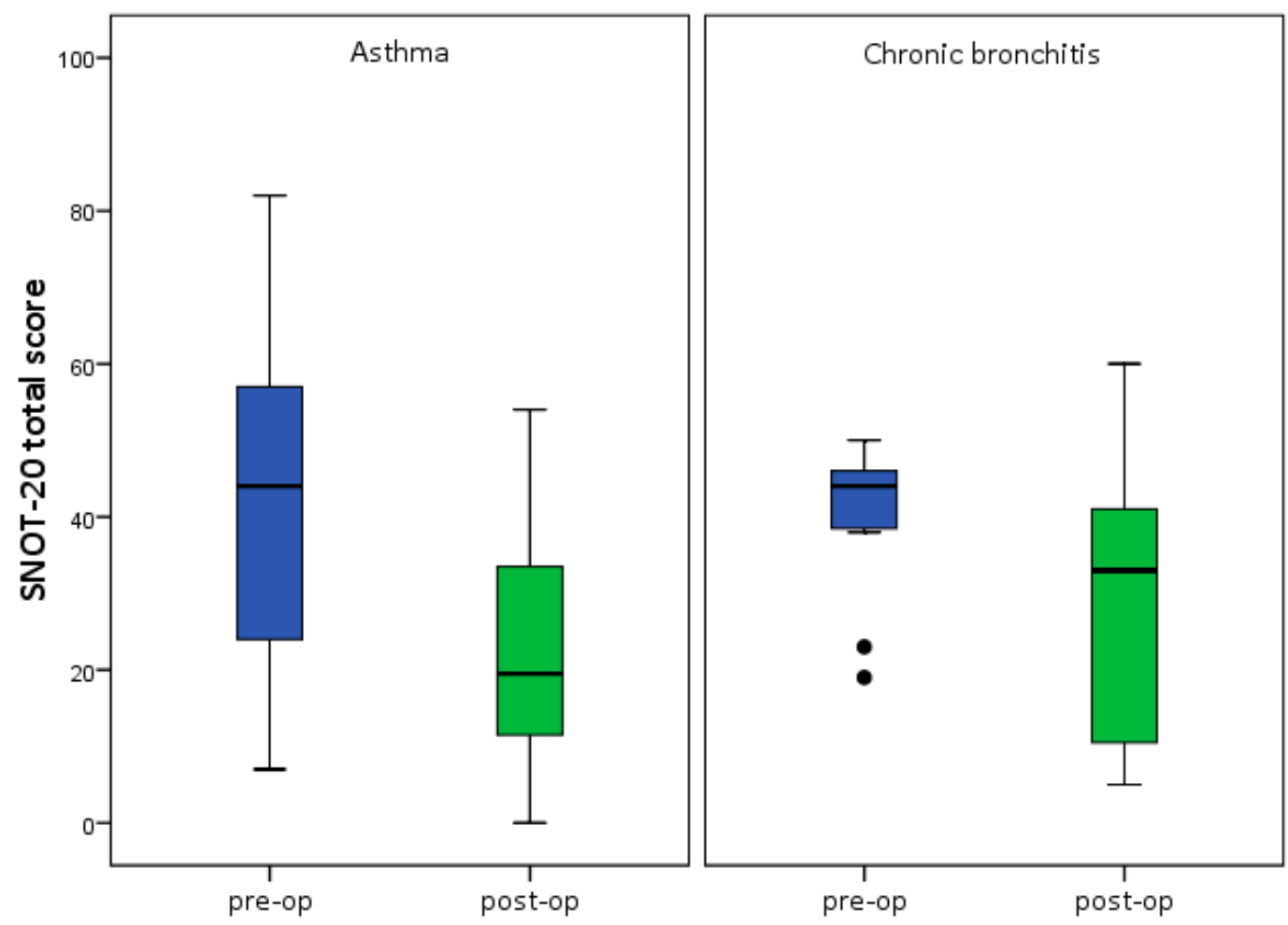

Figure 11. SNOT-20 GAV total score pre-op and post-op in asthma and chronic bronchitis group (black circles are outliers). 
Table 1. Sino-Nasal Outcome Test 20 German Adapted Version (SNOT-20 GAV) symptom score pre-op and post-op.

\begin{tabular}{cccc}
\hline Symptom & Pre-op (Ø) & Post-op (Ø) & $p$-value \\
\hline Need to blow nose & $2.51 \pm 1.4$ & $1.44 \pm 1.2$ & $<0.001$ \\
Sneezing & $2.00 \pm 1.5$ & $0.93 \pm 0.9$ & $<0.001$ \\
Runny nose & $2.21 \pm 1.6$ & $1.00 \pm 1.1$ & $<0.001$ \\
Cough & $2.23 \pm 1.6$ & $1.67 \pm 1.5$ & 0.010 \\
Postnasal discharge & $2.72 \pm 1.7$ & $1.67 \pm 1.4$ & 0.001 \\
Thick nasal discharge & $2.67 \pm 1.6$ & $1.49 \pm 1.4$ & $<0.001$ \\
Ear fullness & $1.91 \pm 1.5$ & $0.81 \pm 1.2$ & $<0.001$ \\
Dizziness & $1.16 \pm 1.4$ & $0.67 \pm 1.1$ & 0.005 \\
Ear pain & $0.93 \pm 1.1$ & $0.51 \pm 0.8$ & 0.033 \\
Facial pain/pressure & $2.37 \pm 1.8$ & $1.12 \pm 1.2$ & $<0.001$ \\
Difficulty falling asleep & $1.88 \pm 1.7$ & $1.26 \pm 1.5$ & 0.003 \\
Wake up at night & $2.60 \pm 1.3$ & $1.74 \pm 1.4$ & $<0.001$ \\
Lack of a good night's sleep & $2.81 \pm 1.6$ & $1.53 \pm 1.5$ & $<0.001$ \\
Wake up tired & $2.49 \pm 1.6$ & $1.65 \pm 1.5$ & 0.001 \\
Fatigue & $2.70 \pm 1.6$ & $1.70 \pm 1.2$ & $<0.001$ \\
Reduced productivity & $2.47 \pm 1.6$ & $1.60 \pm 1.4$ & 0.001 \\
Reduced concentration & $2.14 \pm 1.5$ & $1.21 \pm 1.2$ & $<0.001$ \\
Frustrated/restless/irritable & $2.14 \pm 1.5$ & $1.09 \pm 1.2$ & $<0.001$ \\
Sad & $1.65 \pm 1.6$ & $0.84 \pm 1.1$ & 0.001 \\
Embarrassed & $1.02 \pm 1.4$ & $0.42 \pm 0.8$ & $<0.001$ \\
\hline
\end{tabular}

\section{Discussion}

This study focuses on possible improvements in the quality of life of COPD patients after sinus surgery.

The study found SGRQ improvements in patients with asthma to be 8.3 points and in patients with COPD to be 7.9 points. $69.0 \%$ of the asthma patients and $62.5 \%$ of the COPD patients showed postoperative improvements in a minimum of four points. In 2002, a differentiation of four points in SGRQ was identified by Jones as being clinically relevant [14]. Therefore, this study proves for the first time that in both groups there was a relevant improvement in the quality of life after sinus surgery.

Additionally, this study demonstrates the impact of upper airway on the lower airway independent of the pathology in patients with COPD. The impact of sinus surgery on the lower airway has previously been demonstrated in patients with bronchial asthma and bronchial hyperreagibility. A significant improvement of lung function in patients with bronchial asthma was found in different studies [4,15]. Stahl et al. [16] reported on the relation between severity of the COPD, GOLD (Global Initiative for Chronic Obstructive Lung Disease) classification and SGRQ-score in patients with a medial SGRQ score of $32.9 \%$. An improvement of the peak flow in $75 \%$ was reported in Dejima et al. Study [17]. Improvements of the subjective feeling of the patients with asthma of $70 \%$ have been noted by Uri et al. 2002 [18].

The quality of life for patients in our study was improved after sinus surgery independent of an additional disease pattern such as nasal polyps or ASS intolerance. Similar results have been reported by Batra et al. (2003), which analysed 17 patients with nasal polyps and bronchial asthma as well as nine patients with ASS-intolerance and bronchial asthma, showing the improvement of bronchial asthma independent of ASS intolerance [19].

Comparing the results of SNOT-20 GAV and SGRQ, patients with a high preoperative SNOT-20 GAV score obviously experienced greater improvements in their postoperative quality of life. The correlation coefficient between preoperative SGRQ and the improvement of the postoperative run, as well as for SNOT and SGRQ, found an adequate rank level in both.

In this study, the second data acquisition was taken at a minimum of three months after sinus surgery. Usually the oedema phase takes approximately 30 days, and after three months the healing process is complete [20]. Baumann et al. [21] and Hopkins et al. [22] determined there was no difference or significant outcome of SNOT-20 GAV between the three month and the one year data collection 
results and the five year results. Not all patients in this study had preoperative medication for bronchial asthma or COPD. This was found to be a limitation when questioning medication changes post sinus surgery. A high percentage of the study patients (22\%) needed no medication therapy pre- or postoperatively. In a European study conducted by Patridge et al. 2011, 50\% of asthma patients and $23 \%$ of COPD patients needed no medication when first questioned [23].

In this study, $28 \%$ of the patients had ASS-intolerance with a quarter of those having nasal polyps. Based on previous studies, the prevalence of ASS-intolerance ranges from $0.6 \%$ to $2.5 \%$, whilst the prevalence increases to $20 \%$ in patients with asthma [3,24]. In our study group, the eosinophily in the histopathological examination of the nasal mucosa was $72 \%$ in patients with asthma, and $64 \%$ in the COPD patients. An allergy was known to be present in $80 \%$ of the asthma patients. Various authors have reported the correlation of eosinophily in nasal mucosa and bronchial asthma [25,26]. Various studies have also shown a strong correlation, up to $80 \%$, between patients with an allergy and patients with bronchial asthma $[27,28]$.

In our study, the Lund-MacKay Score was 13.5 points. A score of five points was determined to be nonpathological [29]. Patients with chronic sinusitis were found to have a score ranging from 10 to 13.4 points [30,31]. A higher score was detected [32,33] in patients with bronchial asthma

In this study, $58 \%$ of the patients had sinus surgery as a revision surgery. In previous studies, note that the revision surgery rate ranges from 19\% to 63\% [34-36]. Risk factors for revision surgery include: ASS-intolerance [37], bronchial asthma [38], allergy [39] and nasal polyps [40]. Our study clearly demonstrates the improvement of the SNOT-20 GAV results with a preoperative median score of 44 points and a postoperative score of 22 points. The improvement was high and statistically significant $(p<0.001)$. This improvement in the SNOT-20 GAV score was independent of pulmonary disease, ASS-intolerant, nasal polyp, allergy, CT-Score and revision surgery. Numerous studies have confirmed the success of the operation for patients with chronic sinusitis based on a SNOT-20 score $[30,31,33,41,42]$.

\section{Conclusions}

This study shows the positive impact of sinus surgery for patients with bronchial asthma as well as for patients with COPD. The postoperative improvement was independent of pulmonary disease, nasal polyp, allergy, eosinophily, ASS-intolerance, CT-score or revision surgery. Sinus surgery for chronic rhinosinusitis may help to improve the therapy outcome of patients with bronchial asthma and COPD.

Acknowledgments: The authors would like to acknowledge the valuable contribution of Mei Fang Ong from the institute for Medical Biometry, University Medical Center Homburg/Saar, Germany in performing the statistical analysis. The authors would also like to acknowledge the valuable contribution made by native English speaker Jane C. Crofts in proof-reading this manuscript.

Author Contributions: Basel Al Kadah, study design, data collection, statistical analysis, drafting, final approval, accountability for all aspects of the work, correspondence; Gudrun Helmus, study design, data collection, statistical analysis, drafting, final approval; Quoc Thai Dinh and Bernhard Schick, revision, drafting, final approval, accountability for all aspects of the work.

Conflicts of Interest: The authors declare no conflict of interest.

\section{References}

1. Huzly, A. Sinobronchial Syndrome. Beitr. Klin. Tuberk. 1969, 139, 265-282. [CrossRef]

2. Singleton, M.A. The sinobronchial syndrome: An old fashioned, modern-day entity. South Med. J. 1971, 64, 754-756. [CrossRef] [PubMed]

3. Stuck, B.A.; Bachert, C.; Federspil, P.; Hosemann, W.; Klimek, L.; Mösges, R.; Pfaar, O.; Rudack, C.; Sitter, H.; Wagenmann, M.; et al. German Society of Otorhinolaryngology, Head and Neck Surgery. Rhinosinusitis guidelines-unabridged version: S2 guidelines from the German Society of Otorhinolaryngology, Head and Neck Surgery. HNO 2012, 60, 141-162. [CrossRef] [PubMed] 
4. Ehnhage, A.; Olsson, P.; Kolbeck, K.G.; Skedinger, M.; Stjärne, P. One year after endoscopic sinus surgery in polyposis: Asthma, olfaction, and quality-of-life outcomes. Otolaryngol. Head Neck Surg. 2012, 146, 834-841. [CrossRef] [PubMed]

5. Hurst, J.R.; Perera, W.R.; Wilkinson, T.M.; Donaldson, G.C.; Wedzicha, J.A. Systemic and upper and lower airway inflammation at exacerbation of chronic obstructive pulmonary disease. Am. J. Respir. Crit. Care Med. 2006, 173, 71-78. [CrossRef] [PubMed]

6. Hens, G.; Vanaudenaerde, B.M.; Bullens, D.M.A.; Piessens, M.; Decramer, M.; Dupont, L.J.; Hellings, P.W. Sinonasal pathology in nonallergic asthma and COPD: “United airway disease" beyond the scope of allergy. Allergy 2008, 63, 261-267. [CrossRef] [PubMed]

7. Piotrowska, V.M.; Piotrowski, W.J.; Kurmanowska, Z.; Marczak, J.; Górski, P.; Antczak, A. Rhinosinusitis in COPD: Symptoms, mucosal changes, nasal lavage cells and eicosanoids. Int. J. Chronic Obstr. Pulm. Dis. 2010, 5, 107-117.

8. Kelemence, A.; Abadoglu, O.; Gumus, C.; Berk, S.; Epozturk, K.; Akkurt, I. The Frequency of Chronic Rhinosinusitis/Nasal Polyp in COPD and Its Effect on the Severity of COPD. COPD J. Chronic Obstr. Pulm. Dis. 2011, 8, 8-12. [CrossRef] [PubMed]

9. Kim, J.S.; Rubin, B.K. Nasal and sinus inflammation in chronic obstructive pulmonary disease. COPD 2007, 4, 163-166. [CrossRef] [PubMed]

10. Al Kadah, B.; Bumm, K.; Charalampaki, P.; Schick, B. First experience in endonasal surgery using a new 3D-Chipendoscope Laryngorhinootologie. Laryngo-Rhino-Otol. 2012, 91, 428-433.

11. Jones, P.W. St. George's Respiratory Questionnaire: MCID. COPD J. Chronic Obstr. Pulm. Dis. 2005, 2, 75-79. [CrossRef]

12. Piccirillo, J.F.; Merritt, M.G., Jr.; Richards, M.L. Psychometric and clinimetric validity of the 20-Item Sino-Nasal Outcome Test (SNOT-20). Otolaryngol. Head Neck Surg. 2002, 126, 41-47. [CrossRef] [PubMed]

13. Baumann, I.; Blumenstock, G.; DeMaddalena, H.; Piccirillo, J.F.; Plinkert, P.K. Quality of life in patients with chronic rhinosinusitis Validation of the Sino-Nasal Outcome Test-20 German Adapted Version. HNO 2007, 55, 42-47. [CrossRef] [PubMed]

14. Jones, P.W. Interpreting thresholds for a clinically significant change in health status in asthma and COPD. Eur. Respir. J. 2002, 19, 398-404. [CrossRef] [PubMed]

15. Loehrl, T.A.; Ferre, R.M.; Toohill, R.J.; Smith, T.L. Long-term asthma outcomes after endoscopic sinus surgery in aspirin triad patients. Am. J. Otolaryngol. 2006, 27, 154-160. [CrossRef] [PubMed]

16. Stahl, E.; Lindberg, A.; Jansson, S.-A.; Rönmark, E.; Svensson, K.; Andersson, F.; Lundbäck, B. Health-related quality of life is related to COPD disease severity. Health Qual. Life Outcomes 2005, 3, 56-64. [CrossRef] [PubMed]

17. Dejima, K.; Hama, T.; Miyazaki, M.; Yasuda, S.; Fukushima, K.; Oshima, A.; Hisa, Y. A clinical study of endoscopic sinus surgery for sinusitis in patients with bronchial asthma. Int. Arch. Allergy Immunol. 2005, 138, 97-104. [CrossRef] [PubMed]

18. Uri, N.; Cohen-Kerem, R.; Barzilai, G.; Greenberg, E.; Doweck, I.; Weiler-Ravell, D. Functional endoscopic sinus surgery in the treatment of massive polyposis in asthmatic patients. J. Laryngol. Otol. 2002, 116, 185-189. [CrossRef] [PubMed]

19. Batra, P.S.; Kern, R.C.; Tripathi, A.; Conley, D.B.; Ditto, A.M.; Haines, G.K.; Grammar, L. Outcome analysis of endoscopic sinus surgery in patients with nasal polyps and asthma. Laryngoscope 2003, 113, 1703-1706. [CrossRef] [PubMed]

20. Hosemann, W.; Wigand, M.E.; Gode, U.; Linger, F.; Dunker, I. Normal wound healing of the paranasal sinuses: Clinical and experimental investigations. Eur. Arch. Otorhinolaryngol. 1991, 248, 390-394. [CrossRef] [PubMed]

21. Baumann, I.; Blumenstock, G.; Praetorius, M.; Sittel, C.; Piccirillo, J.F.; Plinkert, P.K. Patients with chronic rhinosinusitis: Disease-specific and general health-related quality of life. HNO 2006, 54, 544-549. [CrossRef] [PubMed]

22. Hopkins, C.; Slack, R.; Lund, V.; Brown, P.; Copley, L.; Browne, J. Long-term outcomes from the English national comparative audit of surgery for nasal polyposis and chronic rhinosinusitis. Laryngoscope 2009, 119, 2459-2465. [CrossRef] [PubMed]

23. Partridge, M.R.; Dal Negro, R.W.; Olivieri, D. Understanding patients with asthma and COPD: Insights from a European study. Prim. Care Respir. J. 2011, 20, 315-323. [CrossRef] [PubMed] 
24. May, A.; Wagner, D.; Langenbeck, U.; Weber, A. Family study of patients with aspirin intolerance and rhinosinusitis. HNO 2000, 9, 650-655. [CrossRef]

25. Bourdin, A.; Gras, D.; Vachier, I.; Chanez, P. Upper airway 1: Allergic rhinitis and asthma: United disease through epithelial cells. Thorax 2009, 64, 999-1004. [CrossRef] [PubMed]

26. Ciprandi, G.; Cirillo, I.; Vizzaccaro, A.; Milanese, M.; Tosca, M.A. Airway function and nasal inflammation in seasonal allergic rhinitis and asthma. Clin. Exp. Allergy 2004, 34, 891-896. [CrossRef] [PubMed]

27. Awad, O.G.; Lee, J.H.; Fasano, M.B.; Graham, S.M. Sinonasal outcomes after endoscopic sinus surgery in asthmatic patients with nasal polyps: A difference between aspirin-tolerant and aspirin-induced asthma? Laryngoscope 2008, 118, 1282-1286. [CrossRef] [PubMed]

28. Vogelmeier, C.; Buhl, R.; Criee, C.P.; Gillissen, A.; Kardos, P.; Köhler, D.; Magnussen, H.; Morr, H.; Nowak, D.; Pfeiffer-Kascha, D.; et al. Leitlinie der Deutschen Atemwegsliga und der Deutschen Gesellschaft für Pneumologie und Beatmungsmedizin zur Diagnostik und Therapie von Patienten mit chronisch obstruktiver Bronchitis und Lungenemphysem (COPD). Pneumologie 2007, 61, e1-e40. (In German). [CrossRef] [PubMed]

29. Ashraf, N.; Bhattacharyya, N. Determination of the "incidental" Lund scores for the staging of chronic rhinosinusitis. Otolaryngol. Head Neck Surg. 2001, 125, 483-486. [CrossRef]

30. Baumann, I.; Blumenstock, G.; Zalaman, I.M.; Praetorius, M.; Klingmann, C.; Sittel, C.; Piccirillo, J.F. Impact of gender, age, and comorbidities on quality of life in patients with chronic rhinosinusitis. Rhinology 2007, 45, 268-272. [PubMed]

31. Bradley, D.T.; Kountakis, S.E. Correlation between computed tomography scores and symptomatic improvement after endoscopic sinus surgery. Laryngoscope 2005, 115, 466-469. [CrossRef] [PubMed]

32. Bonfils, P.; Tavernier, L.; Abdel Rahman, H.; Mimoun, M.; Malinvaud, D. Evaluation of combined medical and surgical treatment in nasal polyposis-III. Correlation between symptoms and CT scores before and after surgery for nasal polyposis. Acta Otolaryngol. 2008, 128, 318-323. [CrossRef] [PubMed]

33. Kountakis, S.E.; Bradley, D.T. Effect of asthma on sinus computed tomography grade and symptom scores in patients undergoing revision functional endoscopic sinus surgery. Am. J. Rhinol. 2003, 17, 215-219. [PubMed]

34. Lee, J.Y.; Lee, S.W.; Lee, J.D. Comparison of the surgical outcome between primary and revision endoscopic sinus surgery for chronic rhinosinusitis with nasal polyposis. Am. J. Otolaryngol. 2008, 29, 379-384. [CrossRef] [PubMed]

35. Seyring, C.; Bitter, T.; Boger, D.; Büntzel, J.; Esser, D.; Hoffmann, K.; Guntinas-Lichius, O. Health Services Research on Paranasal Sinus Surgery in Thuringia: Epidemiologic Key Data and Outcome. Laryngorhinootologie 2012, 91, 434-439. [PubMed]

36. Smith, T.L.; Mendolia-Loffredo, S.; Loehrl, T.A.; Sparapani, R.; Laud, P.W.; Nattinger, A.B. Predictive factors and outcomes in endoscopic sinus surgery for chronic rhinosinusitis. Laryngoscope 2005, 115, 2199-2205. [CrossRef] [PubMed]

37. Gosepath, J.; Pogodsky, T.; Mann, W.J. Characteristics of recurrent chronic rhinosinusitis after previous surgical therapy. Acta Otolaryngol. 2008, 128, 778-784. [CrossRef] [PubMed]

38. Seybt, M.W.; McMains, K.C.; Kountakis, S.E. The prevalence and effect of asthma on adults with chronic rhinosinusitis. Ear Nose Throat J. 2007, 86, 409-411. [PubMed]

39. Wilkinson, T.M.; Patel, I.S.; Wilks, M.; Donaldson, G.C.; Wedzicha, J.A. Airway bacterial load and FEV1 decline in patients with chronic obstructive pulmonary disease. Am. J. Respir. Crit. Care Med. 2003, 167, 1090-1095. [CrossRef] [PubMed]

40. Hosemann, W. Postoperative measures to prevent recurrence of chronic pansinusitis and polyposis nasi. HNO 2003, 51, 279-283. [CrossRef] [PubMed]

41. Bezerra, T.F.; Piccirillo, J.F.; Fornazieri, M.A.; Pilan, R.R.D.M.; Pinna, F.D.R.; Padua, F.G.D.M.; Voegels, R.L. Assessment of quality of life after endoscopic sinus surgery for chronic rhinosinusitis. Braz. J. Otorhinolaryngol. 2012, 78, 96-102. [CrossRef] [PubMed]

42. Ling, F.T.; Kountakis, S.E. Important clinical symptoms in patients undergoing functional endoscopic sinus surgery for chronic rhinosinusitis. Laryngoscope 2007, 117, 1090-1093. [CrossRef] [PubMed]

(C) 2017 by the authors. Licensee MDPI, Basel, Switzerland. This article is an open access article distributed under the terms and conditions of the Creative Commons Attribution (CC BY) license (http:/ / creativecommons.org/licenses/by/4.0/). 